\title{
STRUCTURAL AND MATHEMATICAL MODEL OF THE THERMAL CONDUCTIVITY OF CONCRETE
}

\author{
Vladimir Gryzlov ${ }^{1}$, Alla Kaptyushina ${ }^{2}$ \\ ${ }^{1,2}$ Cherepovets State University \\ Lunacharsky Prospect, 5, Cherepovets, Russia
}

${ }^{1}$ Corresponding author: gryvs@mail.ru

\begin{abstract}
Introduction: The significance of energy saving in residential construction is associated with the reliable determination of design thermal conductivity characteristics of construction materials. The authors describe a concept of the structural and mathematical modeling of concrete thermal conductivity. The concept is based on methods of the structural approach and generalized conductivity theory. Purpose of the study: The study is aimed at developing an adequate structural and mathematical model to determine the thermal conductivity of concrete. Methods: The authors used the statistical method as a representation of the statistical homogeneity of a multi-component composite closely related to thermal homogeneity, which is understood as a medium with effective thermal resistance constant in space. Results: The authors developed a structural and mathematical model to determine the thermal conductivity of concrete. The model accounts for concrete structural factors existing at the time when the structure formation of concrete is, for the most part, complete. The model also accounts for the thermal and physical properties of concrete components as well as macro- and mesostructural features of concrete. The paper presents calculated data for potential macro- and mesostructural factors, which makes it possible to determine the thermal conductivity of concrete characterized by low thermal conductivity and use the results derived for the approximation of prediction trends related to the thermal properties of such concretes in the operation and adaptation period during the use of building envelopes.
\end{abstract}

\section{Keywords}

Thermal conductivity, structural and technological factor, mathematical model, prediction of thermal and physical properties.

\section{Introduction}

The issue of the reliable determination of concrete thermal conductivity is one of the most important in modern construction material engineering. The potential of improving heat-protection efficiency and resource-saving in the manufacturing and operation of building envelopes depends on its successful solution.

The following model of concrete thermal conductivity was suggested in the earlier paper of the author (Gryzlov, 2008):

$$
\lambda(t)=\lambda_{0}-\Delta \lambda_{0}(t) e^{-\left(t-t_{0}\right) / \tau}
$$

where $\lambda(t)$ is concrete thermal conductivity at fixed time $t ; \lambda_{0}$ is concrete thermal conductivity when the structure formation process is, for the most part, complete (28 days of hardening); $\Delta \lambda_{0}(t)$ is an increment that occurs as a result of operations during time $t ; t_{0}$ is time of intense structure formation; $r$ is time of thermal conductivity relaxation.

The minus sign before $\lambda_{0}(t)$ indicates that thermal conductivity adaptation is related to balancing constructive and destructive processes occurring in concrete that, in general, lead to a decrease in internal stress and transition to a stable equilibrium state of exponential nature. Equation (1) can be considered a general equation for the formation and prediction of concrete thermal and physical properties during the operation of building envelopes. The solution to the prediction problem reduces to the optimization of $\lambda_{0}$ and $\tau$. The $\lambda_{0}$ parameter is a structural and technological aspect of the property, which can be found at the stage of structure selection and formation; the $\mathrm{T}$ value depends not only on the internal parameters of $\lambda$ but also on the concrete adaptation mode.

According to many researchers (Buzhevich, 1970; Ivanov, 1974; Karamyan, 1976; etc.), the thermal conductivity of concrete is closely related to its density since pores in concrete are filled with air to a large extent. Such an approach is determinative in selecting the design values of thermal conductivity coefficients, and it is captured in regulatory documents (Ministry of Regional Development of Russia, 2012). Table 1 provides empirical equations to determine the thermal conductivity coefficient for inorganic particulate materials, recommended for a wide range of materials, including concrete with a density of $400 \leq y \leq 1800 \mathrm{~kg} / \mathrm{m}^{3}$. These equations support the concept of the predominant influence of the material density on its thermal conductivity. However, they also indicate a significant variation of data on the thermal conductivity coefficient at the same density $(\Delta \lambda>50 \%)$, which is even more significant in the case of extreme values (Figure 1). 
Table 1. Empirical equations to determine the thermal conductivity of concrete

\begin{tabular}{|c|c|l|}
\hline No. & Author & \multicolumn{1}{c|}{ Equation } \\
\hline 1 & Buzhevich G. A. & $\lambda=0.38 \gamma 10^{-3}-0.12$ \\
\hline 2 & Vlasov O. E. & $\lambda=0.2 \gamma+0.05 \gamma^{2}$ \\
\hline 3 & Ivanov I. A. & $\lambda=0.0005 \gamma-0.25$ \\
\hline 4 & Kaufman B. N. & $\lambda=0.11 \gamma^{1.11} 1.68 \gamma+0.022$ \\
\hline 5 & Karamyan K. O. & $\lambda=0.046+0.16 \gamma^{2}$ \\
\hline 6 & Nekrasov V. P. & $\lambda=1.16 \sqrt{ }\left(0.0196+0.22 \gamma^{2}\right)-0.16$ \\
\hline 7 & Spektor B. V. & $\lambda=0.029+2.19 \cdot 10^{-4} \gamma$ \\
\hline
\end{tabular}

$\lambda$ is the thermal conductivity coefficient; $\lambda$ is density

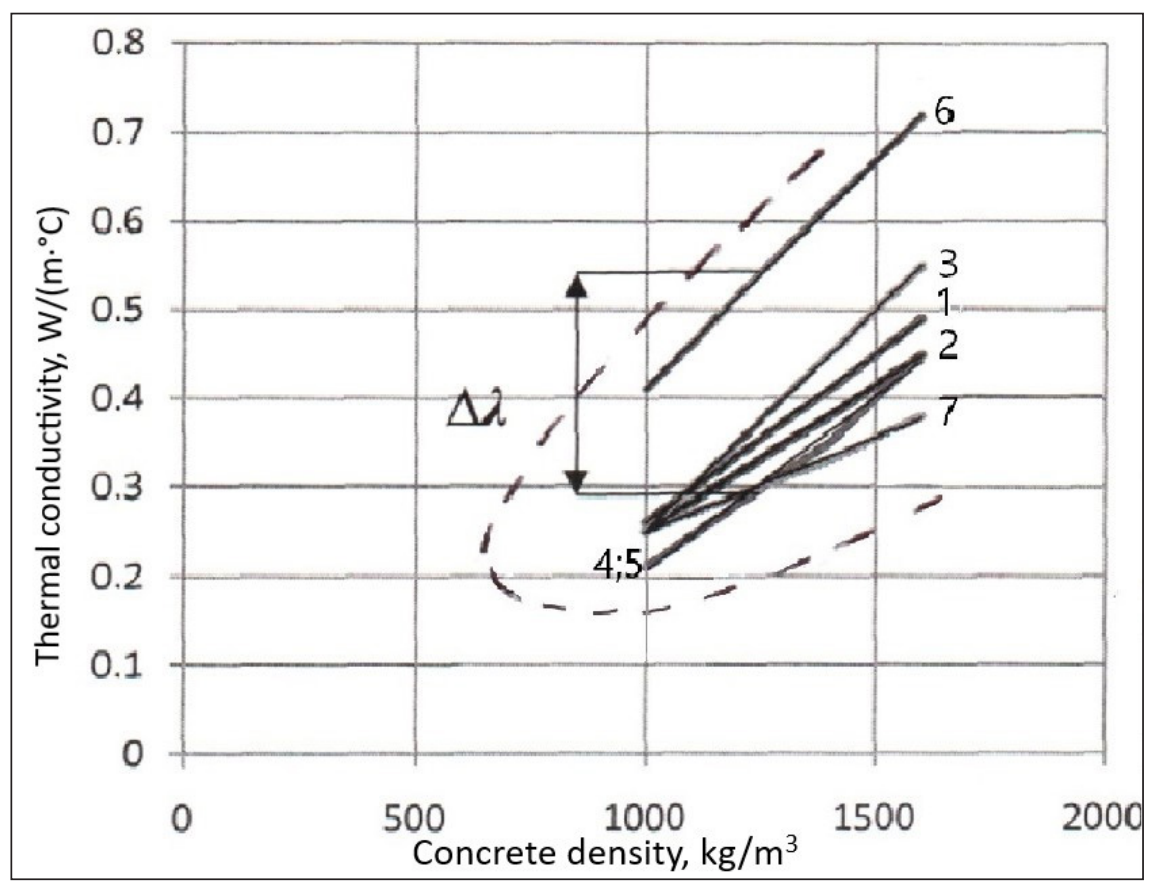

Figure 1 Graphical representation of the equations given in Table 1.

It should be noted that this variation is a consequence of experimental studies conducted by the authors with regard to a certain group of concretes, which confirms that, in the generalized analysis of various types of concrete composites, the structural concept of thermal conductivity exists. The equations given are expressly linear, which indicates a certain bias in the authors' reasoning.

When developing the concept of the influence of concrete porosity on its thermal conductivity, a number of researchers suggested determining thermal conductivity as models of particulates with account for their porosity (Chudnovsky, 1962; Dulnev and Zarechnyak, 1974;
Krischer, 1934). An analysis of these models has shown that the models by Krischer and Bernshtein are the most appropriate for concrete. To a certain extent, these models interpret the dependence of thermal conductivity on porosity and can be transformed into linear functions of the following type:

$$
\lambda_{c}=\lambda_{m}-a P r_{g e n}
$$

In the case of fixed values of matrix and inclusion thermal conductivity (Table 2), the equations become identical and have the same value of the dimensionless factor $a$. 
Table 2. Models of particulates' thermal conductivity with account for porosity

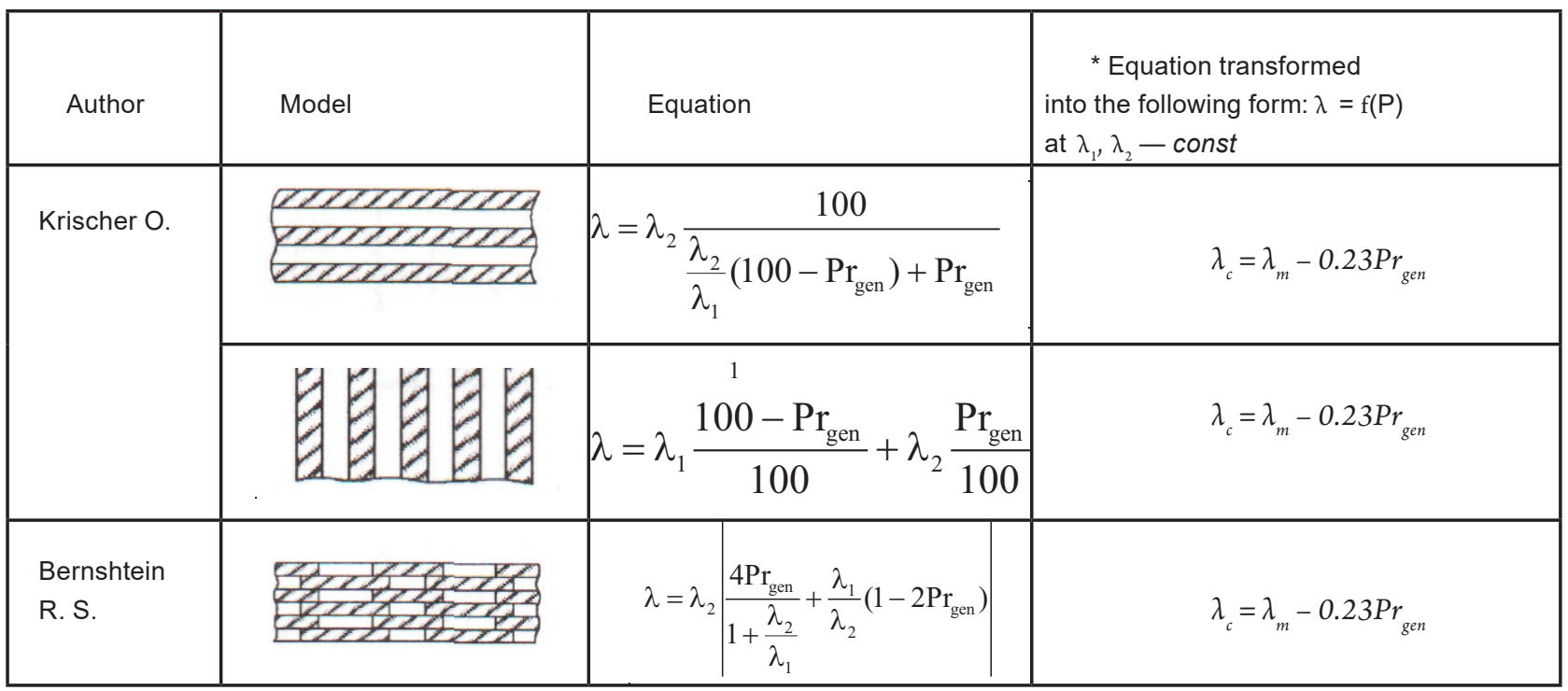

Note. $\lambda_{1} \lambda_{2}$ are matrix and inclusion thermal conductivity values; $\mathrm{Pr}_{g e n}$ is general porosity, fractions of volume; *example: $\lambda_{1}=0.54 \mathrm{~W} /\left(\mathrm{m} \cdot{ }^{\circ} \mathrm{C} ; \lambda_{2}=0.3^{\text {gen }} \mathrm{W} /\left(\mathrm{m} \cdot{ }^{\circ} \mathrm{C}\right)\right.$.

The most important thing arising out of the analysis of these models is the confirmation of the statement that, for concretes with continuous matrix structure and minimum porosity, the matrix, i.e. the cement paste (sand-cement mortar), is the main heat conductor.

With regard to the recipe and technological factors as well as macrostructure, mathematical models describing the dependence of the thermal conductivity coefficient on the inclusion volume are quite interesting (Table 3). While having different mathematical structures, these models, at fixed values, also transform into the linear form, which confirms their qualitative and not quantitative nature.

Table 3. Mathematical models of thermal conductivity with account for the inclusion volume

\begin{tabular}{|c|c|c|}
\hline Author & Equations & $\begin{array}{l}\text { "Equation } \\
\text { transformed into the following form: } \\
\lambda=f(\mathrm{P}) \text { at } \lambda_{\mathrm{m}} / \lambda_{\mathrm{i}}=\text { const }\end{array}$ \\
\hline Odelevsky V. I. & $\lambda_{\mathrm{c}}=\lambda_{\mathrm{m}}\left(1-\frac{P}{\frac{\beta}{\beta-1}-\frac{1-P}{3}}\right)$ & $\lambda_{c}=\lambda_{m}-0.22 P$ \\
\hline Dovzhik V. G. & $\lambda_{\mathrm{c}}=\lambda_{\mathrm{m}}\left(\frac{2 \lambda_{\mathrm{m}}+\lambda_{\text {inc }}-2 P\left(\lambda_{\mathrm{m}}-\lambda_{\text {inc }}\right)}{2 \lambda_{\mathrm{m}}+\lambda_{\text {inc }}+P\left(\lambda_{\mathrm{m}}-\lambda_{\text {inc }}\right)}\right.$ & $\lambda_{c}=\lambda_{m}-0.22 P$ \\
\hline Missenard, A. & $\lambda_{\mathrm{c}}=\lambda_{\mathrm{m}}\left(1+P \frac{1-\beta}{1-^{3} \sqrt{P}-(1-\beta)}\right)$ & $\lambda_{c}=\lambda_{m}-0.22 P$ \\
\hline
\end{tabular}

$P$ is the relative inclusion volume; $\beta=\lambda_{m} / \lambda_{\text {inc }}$; example: $\lambda_{m}=0.54 \mathrm{~W} /\left(\mathrm{m} \cdot{ }^{\circ} \mathrm{C}\right) ; \lambda$ inc $=0.3 \mathrm{~W} /\left(\mathrm{m} \cdot{ }^{\circ} \mathrm{C}\right)$. 
The equations given in Tables 2 and 3, with relevant assumptions, can be transformed into the following form: $\lambda_{\mathrm{c}}=f\left(\lambda_{\mathrm{m}}, \gamma_{\mathrm{c}}\right)$, and they have a more information-bearing structure than the equation (Table 1).

$$
\lambda_{c}=f\left(\operatorname{Prgen}_{\text {gen }}\right)=\lambda_{m}-a\left(1-\gamma / \gamma_{c t d}\right)
$$

where $\gamma_{c t d}$ is concrete true density, a is a dimensionless factor.

$$
\lambda_{c}=f(P)=\lambda_{m}-a(\gamma-1.23 C) / \gamma_{a l}
$$

where $\gamma_{a l}$ is aggregate density in a lump; $C$ is cement consumption per $1 \mathrm{~m}^{3}$ of concrete.

However, each of the equations, taken separately, does not provide sufficient insight into the influence of the differential distribution of pores, defectiveness of the structure, granulometric, phase and mineral composition of the components on the thermal conductivity of concrete. In this context, the purpose of the study was to:

- develop a structural and mathematical model to determine the thermal conductivity of concrete that would reflect the influence of its structural factors existing at the time when the structure formation of concrete is, for the most part, complete.

\section{Methods}

Actual multi-component composites consist of particles of no particular form. Therefore, in order to determine the effective thermal conductivity of such media, it is recommended to use the statistical method. This method can be applied to statistically homogeneous media. Visual interpretation of the statistical homogeneity of a medium means that grains of heterogeneous parts shall be sufficiently small as compared to the characteristic dimensions of the body and shall be distributed in a random manner but uniformly in space. Statistical homogeneity is closely related to thermal homogeneity, which is understood as a medium with effective thermal resistance constant in space. When applying the basic concepts of the generalized thermal conductivity theory (Odelevsky, 1951) to a multi-component matrix system, the equation for the calculation of the effective thermal conductivity, provided that the conditions of structural and statistical homogeneity are met, can be transformed into the following form:

$$
\lambda_{\text {eff }}=\sum \lambda_{i} v_{i}^{2}+\sum 4 \lambda_{i} \lambda_{j} v_{i} v_{j} /\left(\lambda_{i}+\lambda_{j}\right)
$$

where $\lambda_{\text {eff }}$ is the thermal conductivity coefficient of the system, $W /(m \cdot$ degree $) ; \lambda_{i}, \lambda_{i}, v_{i}, v_{i}$ are thermal conductivity coefficients and relative volumes of components, respectively.

This equation is the first approximation to the actual situation. If we present a two-component model of concrete in the form of a layer structure with layers located perpendicular (Figure $2 a$ ) and in parallel (Figure $2 b$ ) to the heat flow (Krischer's model), it is obvious that the first case will be characterized by the maximum thermal resistance, while the second one will be characterized by the minimum one.

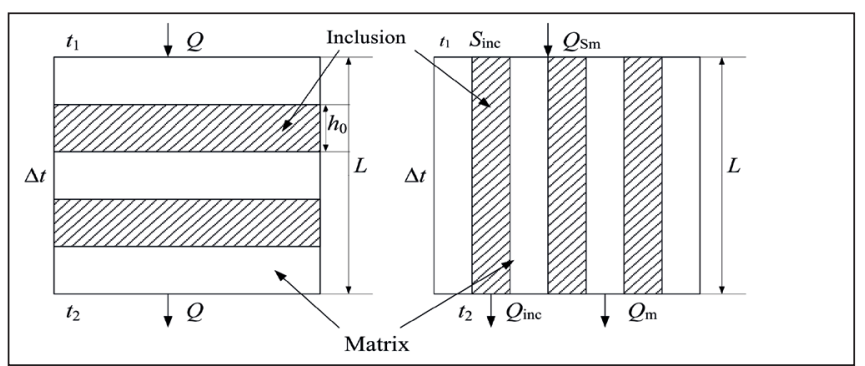

a)

b)

Figure 2. Regarding the calculation of the maximum and minimum thermal resistance of the model: $a$ - the layers are perpendicular to the heat flow; $b-$ the layers are in parallel to the heat flow

The maximum $\left(R_{\max }\right)$ and minimum $\left(R_{\min }\right)$ thermal resistance of this model are described below. Let us assume that $\lambda_{m^{\prime}} \lambda_{\text {inc }}$ are thermal conductivity coefficients with regard to the matrix (binding agent) and inclusion (aggregate); $\mathrm{P}$ is the relative inclusion volume, $P_{m}=1-P$ is the matrix volume; $\beta=\lambda_{m} / \lambda_{i}$ is the ratio of the thermal conductivity coefficients.

Scheme a. Heat flow $Q$ does not depend on the point on the model surface. In this case, the heat flow is expressed clearly through the difference of temperatures on the opposite surfaces.

$Q=\frac{\Delta T}{R}$

where

$$
R=\frac{L-h_{\text {inc }}}{\lambda_{\mathrm{m}}}+\frac{h_{\text {inc }}}{\lambda_{\text {inc }}}
$$

For a unit layer:

$$
R=\left(1-\frac{h_{\text {inc }}}{L}\right) \frac{1}{\lambda_{\mathrm{m}}}+\frac{h_{\mathrm{inc}}}{L} \frac{1}{\lambda_{\text {inc }}}
$$

Since $\left(h_{i n d} / L\right)=v_{i n d}$, equation (6) can be transformed into the following form:

$$
R_{\max }=[1+P(\beta-1)] / \lambda_{\mathrm{m}}
$$

which will correspond to the maximum thermal resistance of the model.

Scheme b. Heat flow $Q$ depends on the point on the model surface. In points related to the inclusion:

$$
Q_{\text {inc }}=\Delta T /\left(L / \lambda_{\text {inc }}\right)
$$

In points related to the matrix:

$$
Q_{\mathrm{m}}=\Delta T /\left(L / \lambda_{\mathrm{m}}\right)
$$

To calculate the average value of $Q$ on the model surface, let us denote the inclusion surface area as $S_{i n c}$, 
and the matrix surface area - as $S_{m}$. The total area is equal to: $S=S_{i n c}+S_{m}$.

The average density of the heat flow on the surface $S$ equals to:

$$
Q=Q_{\text {inc }} \frac{S_{\text {inc }}}{S}+Q_{\mathrm{m}} \frac{S_{\mathrm{m}}}{S} .
$$

Let us apply the values of $Q_{\text {inc }}$ and $Q_{m}$ to equation (10). Then, we will obtain the following:

$$
Q=\Delta T\left(\frac{S_{\text {inc }} \lambda_{\text {inc }}}{S L}+\frac{S_{\mathrm{m}} \lambda_{\mathrm{m}}}{S L}\right) .
$$

Hence, the thermal resistance of the model is as follows:

$$
R=\frac{L}{\frac{S_{\text {inc }}}{S} \lambda_{\text {inc }}+\frac{S_{\mathrm{m}}}{S} \lambda_{\mathrm{m}}}
$$

For unit thickness, we will obtain:

$$
R=\frac{S_{\text {inc }} \lambda_{\text {inc }}+\frac{S_{\mathrm{m}}}{S} \lambda_{\mathrm{m}}}{S}
$$

Taking into account that $S_{\text {inc }} / S$ corresponds to $P$, we will transform equation (12) into the following form:

$$
R_{\min }=\left[1+P(\beta-1) /(P+(1-P) \beta] / \lambda_{m}\right.
$$

which will correspond to the minimum thermal resistance of the model.

By comparing equations (7) and (13), a general structural model of the thermal conductivity of concrete can be found:

$$
\lambda_{\text {eff }}=\lambda_{m} /[1+P(\beta-1) x]
$$

In this equation, $x$ is a dimensionless control factor, which is a product of $x^{\prime}$ (macrostructural level factor) and $x^{\prime \prime}$ (mesostructural level factor). To determine $x^{\prime}$, the expression $1 /[P+(1-P) \beta]$ from equation (13) is used. It should guarantee the minimum error when determining the thermal conductivity of concrete. A nomographic chart of the calculated values of $x^{\prime}$ is given in Figure 3.

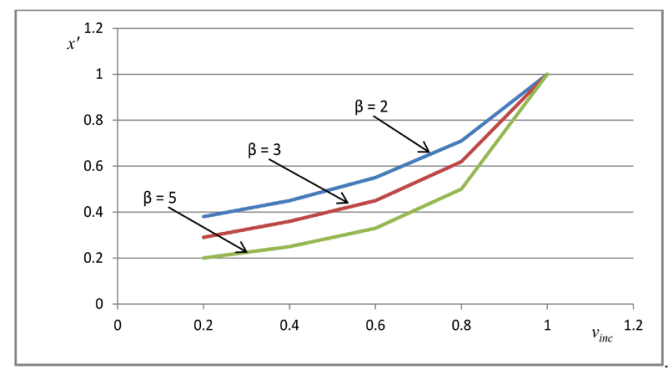

Figure 3. Nomographic chart of the calculated values of $x^{\prime}$

In the model under consideration, $\beta$ is a boundary condition, a peculiar kind of the criterion of sensitivity that divides concretes into ordinary ones $(\beta<1)$ and those with low thermal conductivity $(\beta>1)$, which is adopted as one of the control factors at the microstructural level.

\section{Results and discussion}

The model presented (14) can be considered universal since, through algebraic transformations, a number of known mathematical models of thermal conductivity based on the principles of the generalized conductivity theory (Table 4) are transformed into the form (14), which shows a good approximation of this model with regard to the structural interpretation of the thermal conductivity of concrete. The analysis of the models transformed points at their intermediate value between the values of $R_{\text {max }}$ and $R_{\min }$ in equations (7) and (13), i.e. each of these models reflects a certain principle of inclusion location between the maximum and minimum values of the thermal resistance indicators and, therefore, the thermal conductivity of concrete. Being structural and mechanical, they do not reflect the influence of physical and chemical processes occurring in the contact area, i.e. they do not take into account the level of the mesostructure.

Table 4. Transformation of known mathematical models of thermal conductivity into the form (14)

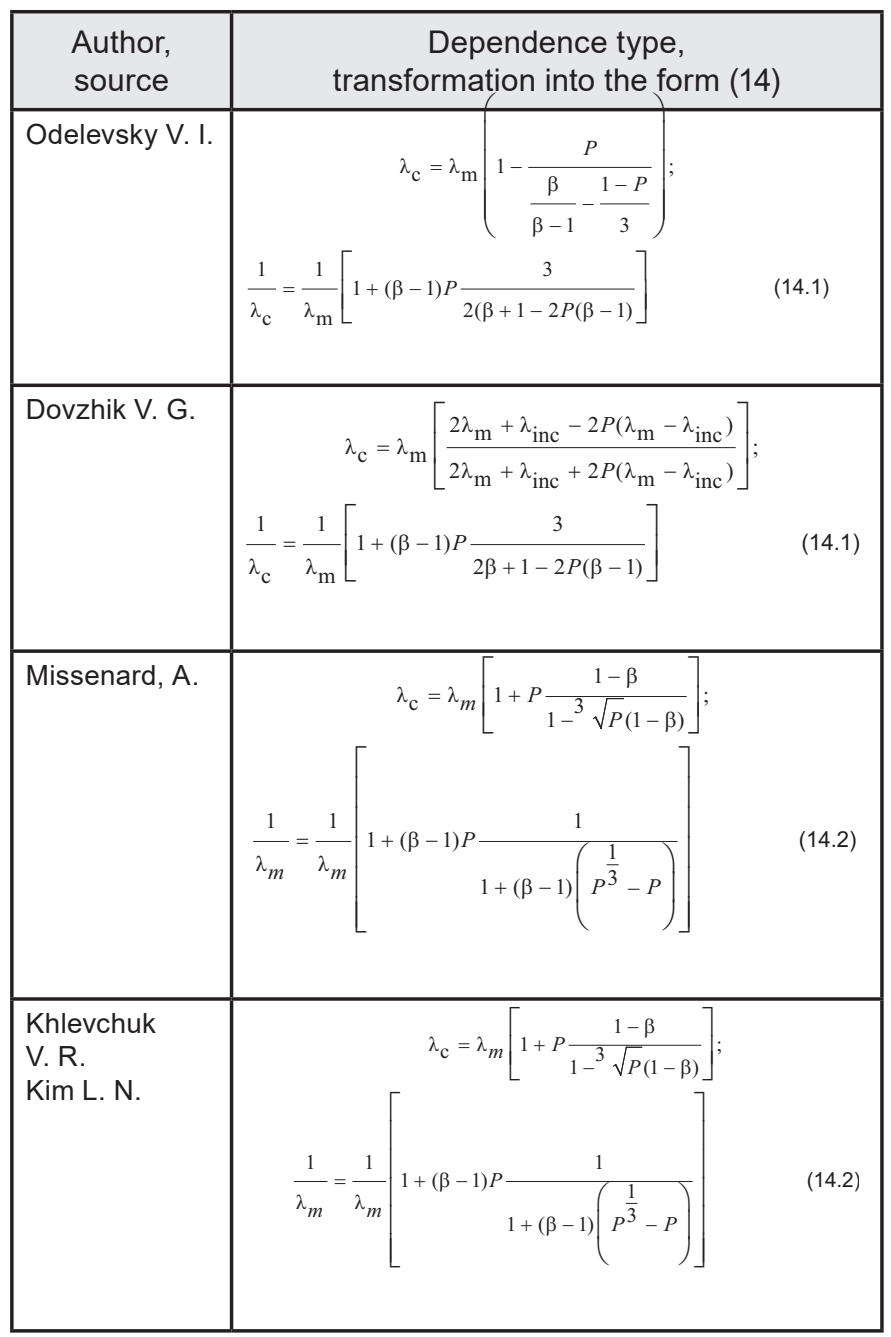


The assessment of this level was conducted experimentally and made it possible to derive a condition for the assignment of $x^{\prime \prime}$. First of all, it was established that layered models consisting of the cement paste and the aggregate, imitating a contact area, have an integrative indicator of thermal conductivity that is less than the additive one by $10-13 \%$ (Kirpichev and Konakov, 1949); at $(\beta>1)$, the following condition is in place: $\lambda_{c} \leq \lambda_{\text {inc }}<\lambda_{1}(\lambda$ is the thermal conductivity coefficient of the contact area).

To assess the impact of the contact area, we will represent the inclusion as a set $n$ of the fractions of the aggregate. Each fraction consists of cubes with the edge $\mathrm{d}_{\mathrm{i}}\left(d_{1}<d_{2}<\ldots<d_{1}\right)$. The cubes are oriented in such a way that the heat flow is perpendicular to a surface. The relative share of the $i^{\text {th }}$ fraction of the aggregate is $\mathrm{a}_{i}, \Sigma_{a i}=1$. Then, with a known relative aggregate volume $P$, the values of $P$ (contact area volume) and $P_{m}$ (matrix volume) can be determined by the following equations:

$$
P_{\text {c.a. }}=2 d P\left(3 \Sigma a_{i} d_{i}^{2}+6 d \sum a_{i} d_{i}+4 d^{2}\right) / \sum a_{i} d_{i}^{3} ;
$$

$$
P_{\mathrm{m}}=1-P_{\text {c.a. }}-P
$$

where $d$ is the thickness of the contact layer that depends not on the size of the aggregate particles but on the aggregate technology and material.

Let us consider a parallelepiped with thickness $L$ consisting of the layers of the matrix, contact layer and the aggregate, joined up in series, in a concrete wall. The cumulative thickness values will be as follows:

for the aggregate layers $-P L$; for the contact area layers $-2 d P L / \Sigma a_{i} d_{i}$ for the matrix layers $-(L-L P-$ $2 d P L) / \Sigma a_{i} d_{i}$
With the thickness values known, we can find the thermal resistance of the parallelepiped $R_{p}$ by the following equation:

$$
\begin{aligned}
R_{p} & =L\left[P / \lambda_{\text {inc }}+2 d P / \lambda_{\text {c.a. }} \sum a_{i} d_{i}+\right. \\
& \left.+\left(1-P-2 d P / \Sigma a_{i} d_{i}\right) / \lambda_{\mathrm{m}}\right] / S
\end{aligned}
$$

To transform equation (16) into the form corresponding to the general structure of $x^{\prime \prime}(14)$, we will introduce following parameters: $D=d / d$, i.e. the ratio between the thickness of the contact layer and the size of the aggregate grain, and $\rho=\lambda / \lambda$, i.e. the ratio between the thermal conductivity coefficient of the matrix and the thermal conductivity coefficient of the contact area.

After the transformation, we will obtain:

$$
\lambda_{\text {eff }}=\lambda_{m} /\left[1+P(\beta-1) x^{\prime}(1+2 D(\rho-1) /(\beta-1)]\right.
$$

Let us adopt $x^{\prime \prime}=1+2 D\left(p_{c}-1\right) /(\beta-1)$,

By substituting values of $x^{\prime}$ and $x^{\prime \prime}$ in equation (13), we will obtain:

$$
\lambda_{\text {eff }}=\lambda_{m}[P+\beta(1-P)] /[\beta+2 D P(\rho-1)]
$$

where $[P+\beta(1-P)] /[\beta+2 D P(\rho-1)]$ can be generally adopted as the structural and technological factor $(\chi)$ at the stage of the formation of integrative quality, in this case the thermal conductivity of concrete.

\begin{tabular}{|c|c|c|c|c|c|c|c|c|c|c|c|}
\hline$P \beta$ & $D$ & $\rho$ & $\chi$ & $P \beta$ & $D$ & $\rho$ & $\chi$ & $P \beta$ & $D$ & $\rho$ & $\chi$ \\
\hline \multirow{9}{*}{$\begin{array}{l}0.8 \\
2.0\end{array}$} & \multirow{3}{*}{0.2} & 2.0 & 0.517 & \multirow{9}{*}{$\begin{array}{c}0.75 \\
2.0\end{array}$} & \multirow{3}{*}{0.2} & 2.0 & 0.543 & \multirow{9}{*}{$\begin{array}{l}0.7 \\
2.0\end{array}$} & \multirow{3}{*}{0.2} & 2.0 & 0.614 \\
\hline & & 1.5 & 0.555 & & & 1.5 & 0.581 & & & 1.5 & 0.654 \\
\hline & & 1.2 & 0.581 & & & 1.2 & 0.606 & & & 1.2 & 0.680 \\
\hline & \multirow{3}{*}{0.15} & 2.0 & 0.535 & & \multirow{3}{*}{0.15} & 2.0 & 0.584 & & \multirow{3}{*}{0.15} & 2.0 & 0.633 \\
\hline & & 1.5 & 0.566 & & & 1.5 & 0.615 & & & 1.5 & 0.665 \\
\hline & & 1.2 & 0.585 & & & 1.2 & 0.635 & & & 1.2 & 0.685 \\
\hline & \multirow{3}{*}{0.12} & 2.0 & 0.548 & & \multirow{3}{*}{0.12} & 2.0 & 0.596 & & \multirow{3}{*}{0.12} & 2.0 & 0.645 \\
\hline & & 1.5 & 0.572 & & & 1.5 & 0.622 & & & 1.5 & 0.671 \\
\hline & & 1.2 & 0.589 & & & 1.2 & 0.638 & & & 1.2 & 0.688 \\
\hline \multirow{9}{*}{$\begin{array}{l}0.8 \\
1.5\end{array}$} & \multirow{3}{*}{0.2} & 2.0 & 0.604 & & \multirow{3}{*}{0.2} & 2.0 & 0.622 & \multirow{9}{*}{$\begin{array}{l}0.7 \\
1.5\end{array}$} & \multirow{3}{*}{0.2} & 2.0 & 0.646 \\
\hline & & 1.5 & 0.662 & & & 1.5 & 0.678 & & & 1.5 & 0.701 \\
\hline & & 1.2 & 0.703 & & & 1.2 & 0.718 & & & 1.2 & 0.739 \\
\hline & \multirow{3}{*}{0.15} & 2.0 & 0.632 & & \multirow{3}{*}{0.15} & 2.0 & 0.649 & & \multirow{3}{*}{0.15} & 2.0 & 0.672 \\
\hline & & 1.5 & 0.679 & & & 1.5 & 0.695 & & & 1.5 & 0.716 \\
\hline & & 1.2 & 0.710 & & & 1.2 & 0.725 & & & 1.2 & 0.745 \\
\hline & \multirow{3}{*}{0.12} & 2.0 & 0.650 & & \multirow{3}{*}{0.12} & 2.0 & 0.666 & & \multirow{3}{*}{0.12} & 2.0 & 0.693 \\
\hline & & 1.5 & 0.689 & & & 1.5 & 0.704 & & & 1.5 & 0.726 \\
\hline & & 1.2 & 0.715 & & & 1.2 & 0.729 & & & 1.2 & 0.750 \\
\hline
\end{tabular}

The results of calculating $x$ for theoretical and practically possible values of $P, \beta, D, \rho$ in concretes with low thermal conductivity are given in Table 5 .

Table 5. Results of calculating the macro- and mesostructural factor $\chi$ in concretes with low thermal conductivity at fixed values of $v_{\text {inc }} \beta, D, \rho$ 


\section{Architecture and Engineering Volume 5 Issue 1}

continuation of the Table 5 .

\begin{tabular}{|c|c|c|c|c|c|c|c|c|c|c|c|}
\hline$P \beta$ & $D$ & $\rho$ & $\chi$ & $P \beta$ & $D$ & $\rho$ & $\chi$ & $P \beta$ & $D$ & $\rho$ & $\chi$ \\
\hline \multirow{9}{*}{$\begin{array}{l}0.8 \\
1.2\end{array}$} & \multirow{3}{*}{0.2} & 2.0 & 0.684 & \multirow{9}{*}{$\begin{array}{c}0.75 \\
1.2\end{array}$} & \multirow{3}{*}{0.2} & 2.0 & 0.700 & \multirow{9}{*}{$\begin{array}{l}0.7 \\
1.2\end{array}$} & \multirow{3}{*}{0.2} & 2.0 & 0.716 \\
\hline & & 1.5 & 0.764 & & & 1.5 & 0.777 & & & 1.5 & 0.834 \\
\hline & & 1.2 & 0.822 & & & 1.2 & 0.833 & & & 1.2 & 0.843 \\
\hline & \multirow{3}{*}{0.15} & 2.0 & 0.722 & & \multirow{3}{*}{0.15} & 2.0 & 0.726 & & \multirow{3}{*}{0.15} & 2.0 & 0.752 \\
\hline & & 1.5 & 0.788 & & & 1.5 & 0.800 & & & 1.5 & 0.811 \\
\hline & & 1.2 & 0.833 & & & 1.2 & 0.843 & & & 1.2 & 0.853 \\
\hline & \multirow{3}{*}{0.12} & 2.0 & 0.747 & & \multirow{3}{*}{0.12} & 2.0 & 0.760 & & \multirow{3}{*}{0.12} & 2.0 & 0.774 \\
\hline & & 1.5 & 0.802 & & & 1.5 & 0.813 & & & 1.5 & 0.825 \\
\hline & & 1.2 & 0.840 & & & 1.2 & 0.849 & & & 1.2 & 0.859 \\
\hline
\end{tabular}

Thus, knowing or assuming the structural and technological characteristics of concretes with low thermal conductivity, using equations (1) and (18), it is possible to approximate the predictive trends of heat-protective properties of these concretes in the operation and adaptation period during the use of building envelopes.

\section{Conclusions}

1. The authors developed an adequate structural and mathematical model to determine the thermal conductivity coefficient of concrete. The model accounts for concrete structural factors existing at the time when the structure formation of concrete is, for the most part, complete.

2. This model, albeit a bit complicated, makes it possible to assign the value of the thermal conductivity coefficient of concrete on a case-by-case basis, taking into account its structural and technological characteristics.

3. It has been confirmed that in concretes with continuous structure, the matrix is the main heat conductor and thermal conductivity factor; the effectiveness of the matrix can be improved or reduced through its modifications or application of the binder with a lower thermal conductivity coefficient.

4. For concretes with low thermal conductivity, the aggregate with the thermal conductivity that is significantly lower than the thermal conductivity of the matrix shall be selected and used, and standard operating procedures, ensuring an increase in the degree of airborne dispersion of the mesostructure and, therefore, an increase in its thickness, shall be applied. 


\section{References}

Bernshtein, R. S. (1948). Thermal conductivity of a layer. In: G. G. Knorre (ed.) Studies of natural fuel combustion processes. Moscow-Leningrad: Gosenergoizdat, pp. 82-88.

Buzhevich, G. A. (1970). Lightweight concrete with porous aggregates. Moscow: Stroyizdat, 272 p.

Chudnovsky, A. F. (1962). Thermal and physical characteristics of disperse materials. Moscow: Fizmatgiz, 456 p.

Dovzhik, V. G. (1972). Thermal conductivity of keramzit. Stroitel'nye materialy, 3, pp. 21-23.

Dulnev, G. N. and Zarechnyak, Yu. P. (1974). Thermal conductivity of mixtures and composite materials. Leningrad: Energiya, 264 p.

Gryzlov, V. S. (2008). Universal model of the thermal conductivity of lightweight concrete. Stroitel'nye Materialy, 1, pp. 44-46.

Ivanov, I. A. (1974). Technology of lightweight concrete with artificial porous aggregates. Moscow: Stroyizdat, 287 p.

Itskovich, S. M. (1977). No-fine concrete. Moscow: Stroyizdat, 119 p.

Karamyan, K. O. (1976). Temperature- and moisture-induced deformations of the building envelope made of lightweight concrete with natural porous aggregates. Yerevan: Ayastan, 308 p.

Kaufman, B. N. (1955). Thermal conductivity of construction materials. Moscow: State Publishing House of Literature on Construction and Architecture, $160 \mathrm{p}$.

Khlevchuk, V. R., Kim, L. N. and Shteinman, B. I. (1983). Calculation of the thermal conductivity of lightweight concrete depending on structural and technological factors. Lightweight concrete house construction. Moscow: Central Research and Design Institute of Residential Buildings, $121 \mathrm{p}$.

Kirpichev, P. V. and Konakov, P. K. (1949). Mathematical basics of the similarity theory. Moscow-Leningrad: Publishing House of the USSR Academy of Scienses, $104 \mathrm{p}$.

Krischer, O. (1934). Der Einfluß von Feuchtigkeit, Körnung und Temperatur auf die Wärmeleitfähigkeit körniger Stoffe (Die Leitfähigkeit des Erdbodens). Beihefte zum Gesundheits-Ingenieur, Series I, No. 33.

Ministry of Regional Development of Russia (2012). Regulations SP 50.13330.2012. Thermal performance of the buildings. Revised edition of SNiP 23-02-2003 (Construction Rules and Regulations). Moscow: Federal Autonomous Organization "Federal Center for Standardization", $95 \mathrm{p}$.

Missenard, A. (1968). Thermal conductivity of solids, liquids, gases and their compositions. Moscow: Mir, 464 p.

Nekrasov, A. A. (1940). Revisiting the dependence of the thermal conductivity coefficient of disperse systems on the external pressure. Technical Physics, 10 (2), pp. 168-173.

Odelevsky, V. I. (1951). Calculation of the generalized conductivity of heterogeneous systems. Technical Physics, 21 (6), pp. 667-677. 


\section{Architecture and Engineering Volume 5 Issue 1}

Spektor, B. V., Svintsitskaya, L. G. and Gutgarts, G. L. (1962). Thermal and physical characteristics of keramzit perlite concrete. Kiev: Academy of Construction and Architecture of the Ukrainian Soviet Socialist Republic.

Starostin, F. D. (1935). Calculation of the thermal conductivity of porous solids. Otopleniye $i$ Ventilyatsiya, 3, pp. 24-25.

Vlasov, O. E. (1938). Fundamentals of construction heat engineering. Moscow: Military and Engineering Academy of the Workers' and Peasants' Red Army, $94 \mathrm{p}$. 


\title{
СТРУКТУРНО - МАТЕМАТИЧЕСКАЯ МОДЕЛЬ ТЕПЛОПРОВОДНОСТИ БETOHA
}

\author{
Владимир Сергеевич Грызлов ${ }^{1}$, Алла Германовна Каптюшина \\ 1,2Череповецкий государственный университет \\ Проспект Луначарского, 5, Череповец, Вологодская область, Россия
}

1E-mail: gryvs@mail.ru

\begin{abstract}
Аннотация
Актуальность энергосбережения в строительстве жилых зданий непосредственно связана с достоверным определением расчетных теплотехнических характеристик строительных материалов. Изложена концепция структурно - математического моделирования теплопроводности бетона, в основу которой, положены методологии структурного подхода и обобщенной теории проводимости. Цель исследования. Разработка адекватной структурно - математической модели по расчету теплопроводности бетона. Метод. Использован статистический метод, как интерпретация статистической однородности многокомпонентного композиционного материала, которая тесно связана с термической однородностью, под которой понимается среда с постоянным по пространству эффективным термическим сопротивлением. Результаты. Разработана структурно - математическая модель по расчету теплопроводности бетона, учитывающая влияние его структурных факторов, сформированных на момент завершения, в основном, процесса структурообразования. В разработанной модели учитываются теплофизические свойства компонентов бетона, его макро- и мезоструктурные особенности. Приведены расчетные данные практически возможных макро - мезо - структурных факторов, что позволяет определять величину теплопроводности малотеплопроводного бетона и использовать полученные результаты для аппроксимации прогнозных трендов теплозащитных свойств этих бетонов в эксплуатационно - адаптационном периоде работы ограждающих конструкций.
\end{abstract}

\section{Ключевые слова}

Теплопроводность, структурно - технологический фактор, математическая модель, прогноз теплофизических свойств. 